\title{
Age-related changes in source memory retrieval: an ERP replication and extension
}

\author{
Domonick J. Wegesin $^{\mathrm{a}, \mathrm{b}, *}$, David Friedman ${ }^{\mathrm{b}}$, Nina Varughese ${ }^{\mathrm{a}, \mathrm{b}}$, Yaakov Stern ${ }^{\mathrm{a}}$ \\ ${ }^{a}$ Division of Cognitive Neuroscience, G.H. Sergievsky Center, Department of Neurology, Columbia University, New York, NY 10032, USA \\ ${ }^{\mathrm{b}}$ Cognitive Electrophysiology Laboratory, New York State Psychiatric Institute, New York, NY 10032, USA
}

Accepted 16 November 2001

\begin{abstract}
Event-related potentials (ERPs) were recorded (62 scalp sites) from young $(M=22)$ and older $(M=66)$ adults during tests of item recognition and source memory, in a replication and extension of a previous study [Psychol. Aging 14 (1999) 390-413]. Participants studied two temporally distinct lists of sentences (each with two unassociated nouns). At test, in response to studied and unstudied nouns, participants made old/new, followed by source (i.e., list) judgments. Several measures were employed to enhance the source memory performance of the older adults. These were successful, as the old adults showed source memory performance comparable to that of the young subjects from the previous study (67\%). Nonetheless, the younger adults significantly outperformed the older adults on measures of item and source memory performance. The ERPs revealed that both age groups showed a robust early, posterior-maximal episodic memory (EM) effect. However, despite their enhanced source memory performance, the ERPs of the old failed to show a robust late, right-prefrontal EM effect, which was again present in the ERPs of the young. By contrast, the older adults showed a central negative component not seen in the ERPs of the young. These results are consistent with the frontal lobe deficit hypothesis of aging and provide some evidence that old and young may use distinct cortical networks during source memory retrieval. (C) 2002 Elsevier Science B.V. All rights reserved.
\end{abstract}

Theme: Neural basis of behavior

Topic: Aging

Keywords: Event-related potential; Source memory; Aging; Prefrontal cortex

\section{Introduction}

Older adults are less adept at monitoring the context of information they have received and are less able to recover the context or 'source' of previously experienced events, e.g., temporal context $[15,60,65]$, spatial context [44,72], or perceptual context [38]. Similarly, studies of reality monitoring have shown that older adults are impaired at remembering if recalled items were internally generated (imagined) or externally generated (heard or seen) [22]. However, they are less impaired or are not impaired at all on simple item recognition memory, i.e., in identifying

\footnotetext{
*Corresponding author. G.H. Sergievsky Center, 19th Floor, 630 West 168th Street, New York, NY 10032, USA. Tel.: +1-212-305-0883; fax: +1-212-305-2426.

E-mail address: wegesin@sergievsky.cpmc.columbia.edu (D.J. Wegesin).
}

whether an item is old or new $[9,15,60]$. A recent metaanalysis demonstrated that the effect size for item recognition memory deficits in aging $(d=0.57)$ was smaller than that for remembering either the stimulus-related context $(d=0.80)$ or spatiotemporal context $(d=1.17)$ of the to-beremembered material [58]. This source memory impairment has been implicated as contributing to other memory problems seen in older adults, such as telling the same story twice [31] or attributing false fame to a previouslypresented non-famous name [14].

Patients with frontal lobe damage are also impaired in making source memory judgments [3,39,33], as are nonhuman primates with discrete mid-dorsal frontal lesions [45]. Hence, source memory is thought to depend upon a frontally-based system [14,25], whereas item memory appears to depend more upon the medial temporal lobe system [59]. Given the older adults' disproportionate difficulty with source compared to item memory, it appears 
that age-related memory decline is due, at least in part, to frontal lobe dysfunction.

Neuroimaging studies also provide evidence for frontal lobe deficits in the old. For example, recent positron emission tomography (PET) imaging studies revealed that the right prefrontal cortex is involved in the retrieval of temporal-order memories [6] and that older adults show reduced right prefrontal activity in such temporal-order memory tasks compared to the young [4]. Similarly, in a test of word recall, young adults showed activation in anterior frontal regions, which was not seen in older adults [51]. Accordingly, right prefrontal cortex appears to be engaged under more challenging retrieval conditions, and a deficit in right prefrontal cortex may help explain the differences in the effect of aging on recognition compared to recall and source retrieval performance [9].

Event-related potential (ERP) studies of memory have revealed two major electrophysiological correlates of contextual recollection. The first component is the wellstudied left parietal episodic memory (EM) effect, for which old words are more positive-going than new words from approximately 400 to $800 \mathrm{~ms}$ (for a review, see Ref. [16]). The amplitude of this EM effect is larger in association with items rated as being consciously remembered $[50,53,54,61]$, for correctly recognized items that are subsequently recalled [49], and for words whose study context is correctly retrieved [61,69,70,68]. Intracranial studies have reported similar EM effects recorded directly from the hippocampus and surrounding subcortical structures over a similar time course as the surface effect $[23,56]$. Further, the left parietal EM effect has been reported to be reduced in epilepsy patients who have undergone medial temporal lobectomy [55,29], and in seizure patients with known medial temporal lobe pathology [66], suggesting that the EM effect recorded at the scalp receives contributions from structures within the medial temporal lobe memory system.

The second EM effect of particular relevance to source memory tasks occurs at right prefrontal scalp sites starting around $600 \mathrm{~ms}$ and continuing through the end of the recording epoch $[1,29,61,71,68]$. The functional interpretation of the right prefrontal activity remains unclear; in some ERP studies it has been proposed to reflect retrieval success [34,70]. Others have interpreted the right prefrontal EM effect to reflect post-retrieval processing [61]. This involves manipulating the information retrieved from the hippocampal system, or as in Moscovitch's theory [41], 'working with memory'. Such processes could include evaluating how the retrieved information relates to the task at hand or how the retrieved information can be used to guide subsequent behavior.

Few studies have examined the effects of aging on EM effects associated with source retrieval, and the limited results that are available have been mixed. Mark and Rugg [34] presented words during a lexical-decision task in either a male or female voice, and then required particip- ants to make old-new recognition decisions to visually presented words. For items judged old, subjects made a subsequent voice (i.e., source) judgment. Both young and old subjects showed a left parietal EM effect that did not differ in magnitude between the two groups. Likewise, both groups showed right prefrontal EM effects that were similar in magnitude and topography. The authors concluded that the neural centers subserving source retrieval were situated in the right prefrontal cortex and were relatively spared by the aging process.

However, two other studies $[61,62]$ have failed to show the right prefrontal EM effect in the ERPs of older adults. For Trott et al.'s task [61], as in the current design, young and old participants studied two lists of sentences each of which contained two nouns and were subsequently tested on item (old/new) and source (list 1/list 2) memory. The left parietal EM effect was present in both young and old subjects. However, only the young produced the right prefrontal EM effect that differed as a function of subsequent source attribution. Trott et al. suggested that this later EM effect was related to the search for and/or retrieval of temporal source information and that the lack of this prefrontal activity in the old, in addition to their poorer source performance, was consistent with the proposal that older adults use a less efficient strategy to retrieve and/or search for source information than the young.

The current study is a replication and extension of the Trott et al. investigation [61]. In that study, though older adults performed above chance levels, their performance was relatively poor (uncorrected percentage of hits with correct source $=55 \%$ ). Several changes were implemented in the temporal source task used by Trott et al. [61] in an attempt to increase the source performance of the old participants. First, current participants had an unlimited amount of time to study the sentences. Second, each sentence was presented on the monitor in its entirety, as opposed to presenting each word of the sentence sequentially. Each of the sentences appeared twice within the study list to give subjects more exposure to the study words prior to the test. Further, elaborative encoding was promoted by asking subjects to make a pleasant/unpleasant (liking) judgment for each sentence. More significantly, the 16-word study lists used by Trott et al., were halved to eight words per list to decrease the memory load, and participants were coached in the use of different mnemonic strategies that could be used to improve their memory performance. We hypothesized that if the lack of a right prefrontal EM effect in the old was related to poor source memory performance, then enhanced performance should evoke the EM effect observed in Trott et al.'s young subjects. Finally, to improve the spatial detail observed in maps of memory-related ERP activity, we recorded from 62 channels and used current source density analysis to resolve better the scalp distributions of the various EM effects that were expected to be recorded. 


\section{Materials and methods}

\subsection{Participants}

Fourteen young (18-28 years) and 14 old (60-80 years) women recruited by community flyers, newspaper advertisements and word of mouth participated in the study. All subjects reported themselves to be native English speakers, in good physical health and were free from medications known to affect the central nervous system. All participants were paid for their time. The New York State Psychiatric Institute's institutional review board approved the project, and all subjects provided written, informed consent.

\subsection{Screening procedures}

Table 1 indicates that no differences were revealed between young and old participants on the Modified MiniMental Status Exam [35] or on the Vocabulary subtest of the Wechsler Adult Intelligence Scale (WAIS-III; [63]). A semi-structured interview (SHORT-CARE; [21]) was administered to older participants to ensure that they were free from depression and dementia, and not limited in the activities of daily living (see Table 1 for details).

\subsection{Experimental procedures}

During the study phase, participants studied two separate lists of sentences of the following type-Noun 1 Verb Noun 2 (e.g., 'The chef created a spread'), in which the two nouns were unassociated (as determined by a previous study [61]). Each list contained four sentences, and each sentence contained two nouns. Within each sentence the two nouns were underlined, for a total of eight nouns per list. Before studying each list, the label 'LIST 1' or 'LIST 2' appeared on the computer screen. Subjects were in-

Table 1

Demographic and neuropsychological characteristics of young and old participants

\begin{tabular}{|c|c|c|c|c|c|}
\hline \multirow[t]{2}{*}{ Measure } & \multicolumn{2}{|c|}{ Young } & \multicolumn{2}{|l|}{ Old } & \multirow[t]{2}{*}{$P$} \\
\hline & $M$ & S.D. & $M$ & S.D. & \\
\hline Age (years) & 21.5 & 2.9 & 66.0 & 19.4 & \\
\hline Education (years) & 15.5 & 1.8 & 14.6 & 3.5 & 0.429 \\
\hline SES $^{\mathrm{a}}$ & 58.3 & 16.7 & 45.0 & 16.6 & 0.043 \\
\hline Modified $\mathrm{MMS}^{\mathrm{b}}$ & 55.2 & 1.7 & 54.4 & 2.4 & 0.321 \\
\hline WAIS-III vocabulary ${ }^{\mathrm{b}}$ & 55.6 & 7.4 & 56.8 & 6.1 & 0.659 \\
\hline Depression $\left(\right.$ SHORT-CARE) ${ }^{\mathrm{c}}$ & & & 2.2 & 1.9 & \\
\hline 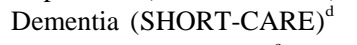 & & & 0.7 & 0.2 & \\
\hline ADL $(\text { SHORT-CARE })^{e}$ & & & 1.8 & 2.7 & \\
\hline
\end{tabular}

${ }^{\text {a }}$ SES-Socioeconomic status (lower scores represent higher SES).

${ }^{\mathrm{b}}$ MMS-Mini mental state; WAIS-Wechsler adult intelligence scale.

${ }^{\mathrm{c}}$ Cutoff for depression is 6 .

${ }^{\mathrm{d}}$ Cutoff for dementia is 7 .

${ }^{\mathrm{e}}$ Cutoff marking significant limitations in ADL—activities of daily living is 26 . structed to memorize the two nouns, as well as the list in which they occurred, for a subsequent memory test. To enhance elaborative encoding, participants were asked to make subjective judgments of the study sentences, indicating whether or not they liked the sentence. They were given unlimited time to study the sentences, and their 'like it/don't like it' judgments prompted the display of the next sentence. In order to aid encoding of the study nouns, each sentence appeared twice within the list in randomized order. At the end of LIST 1, a line drawing depicting a non-verbal cartoon appeared, which was used to demarcate the two lists.

In an attempt to further enhance performance, mnemonic strategies were included in the experimental instructions. Strategies included silent repetition, verbalization (saying the words out loud), visualization/imaging of the study nouns, creating associations among list items (e.g., phonetic or semantic associations), creating stories to bind list items together, separating the list items spatially within the mind's eye, and using the plural form of the noun for items appearing in list 2.

During the test phase, nouns were presented sequentially in pairs, each with a $300 \mathrm{~ms}$ duration separated by a 2000 ms ISI. All possible combinations of pairings were used (e.g., old noun 1/old noun 2 from the same sentence; old noun 1/old noun 2 from different sentences; old/new; new/new, etc.). A total of 256 sentences was divided into two sets, balanced for word frequency and length, and served as either study or foil sentences (counterbalanced across subjects). The target (i.e., old) and foil nouns were rotated across pair types (i.e., old/old same sentence; old/old different sentence; old/new, etc.) so that, across subjects, each noun served equally often in each of those pair types. Subjects made speeded and accurate old/new recognition judgments to each of the two nouns (responding hands counterbalanced across subjects). If either noun was judged old, that noun was re-presented and a nonspeeded temporal context (i.e., list) judgment was made. List judgments were cued by prompts presented on the computer screen.

\subsection{ERP recordings}

Electroencephalograms (EEGs) were recorded from 62 scalp sites (Fig. 1) using an Electro cap (Electrocap International) including left and right mastoids, referred to nosetip, from extended 10-20 system placements (e.g., Ref. [43]). Horizontal and vertical electooculograms (EOGs) were recorded bipolarly with electrodes placed, respectively, at the outer canthi of both eyes and above and below the right eye. EOGs and EEGs were recorded continuously (5-s time constant; $50 \mathrm{~Hz}$ upper cutoff) with Sensorium amplifiers, and digitized at $200 \mathrm{~Hz}$. Data were epoched off-line with $100 \mathrm{~ms}$ pre- and $2000 \mathrm{~ms}$ poststimulus intervals for the test phase. EEG was corrected 


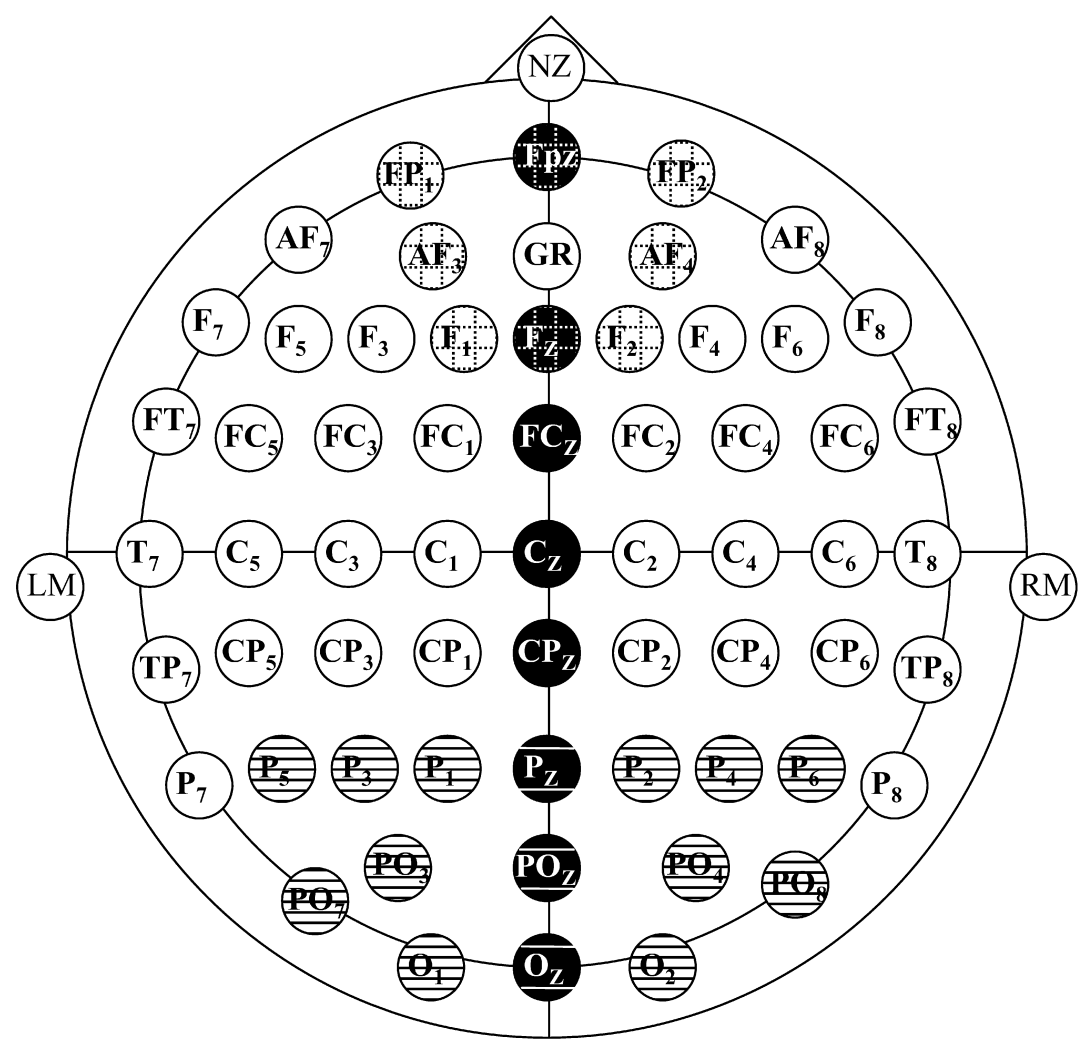

Fig. 1. The electrode montage used in the study highlighting subsets of electrodes employed in frontal (cross hatched), midline (black shading) and parietal-occipital (vertical lines) topographic (i.e., normalized) analyses (see Materials and methods for details). NZ is the reference electrode used during recording.

off-line for the intrusion of eye movement artifacts using the procedure developed by Gratton et al. [19].

\subsection{ERP analyses}

All of the ERP data reported below were collapsed across nouns 1 and 2. As the manipulations to enhance source performance were effective for both young and old subjects, too few young adults made a sufficient number of incorrect source judgments to permit analyses of the ERPs associated with correctly judged old words that were subsequently assigned to the incorrect source. Analyses of the older adults' ERP data to old items assigned to the correct source compared to old items assigned to the incorrect source did not reveal reliable effects. Therefore, group comparisons were restricted to averaged ERPs based on correct recognition (Hits) and to correctly identified new or foil items (Correct Rejections). Only trials with correct responses were included in the averages and in all analyses described below. For all analyses of variance (ANOVAs), the Greenhouse-Geisser method was used to adjust the degrees of freedom for non-sphericity.

\subsubsection{Definition of EM effects}

Based on our previous studies $[61,12]$ and those of others [16] four EM effects were of a priori interest: a centro-parietal EM effect, a left parietal EM effect, a right prefrontal EM effect and a parietal negative EM effect. However, the high-density electrode array used enabled a more detailed description of the electrophysiological responses in the current memory task. As a result, additional EM effects related to discriminating old and new words were revealed. To delineate the spatio-temporal aspects of these additional components, the following analytic approach was used.

Initially, surface potential (SP) and current source density (CSD) maps were generated for each $100 \mathrm{~ms}$ of post-stimulus activity to visualize the topography of the various EM effects. Mapping and analysis of CSD data are incorporated to provide a spatially-sharpened picture of positive and negative current densities across the scalp $[42,47]$. Because CSD data reflect activity generated primarily by local (i.e., cortical) neuronal populations, they are useful for examining EM effects thought to emanate from cortical structures, e.g., the right prefrontal EM effect. Based on visual inspection of the maps, electrodes where EM effects appeared maximal were selected for subsequent analyses.

Next, the timing of the EM effects at the selected recording sites was examined by computing the averaged voltage for each $100 \mathrm{~ms}$ post-stimulus bin $(n=20)$ in both young and old groups. These averaged data were submitted 
to a Condition by Bin repeated measures ANOVA for each group separately. Significant EM effects were specified by identifying those Bins across the recording epoch in which old and new conditions differed, using a Bonferroni-corrected $P$-value $(P=0.0025)$ to control for repeating the $t$-tests across the 20 Bins.

\subsubsection{EM effect duration and timing}

A number of the effects revealed in the preceding analyses sustained significance over several 100-ms bins. In the ERP literature, averaged windows commonly span several hundred milliseconds [48]. The disadvantage of this procedure is that one risks averaging several distinct EM effects into one window, thereby washing out potentially interesting memory-related EM effects. Hence, in order to make use of larger windows without combining several components into a single window, a series of topographic analyses was performed to determine statistically the temporal extent of the EM effects defined above. Analyses were conducted for the young and old groups separately, as the timing and topography of the EM effects varied for the two groups. Data were initially normalized across Bins using the root mean square method described by McCarthy and Wood [36]. This manipulation removes overall amplitude differences between Bins to allow a comparison of the shape of the distribution across the scalp. A significant difference in scalp distribution, suggestive of a change in the underlying generators, is revealed by an interaction of electrode site and Bin. The bins included in these analyses were based on the Bonferonni-corrected tests described above. That is, old/new differences were tested at each $100-\mathrm{ms}$ bin at the electrodes where the EM effect appeared to be maximal. Fig. 1 shows the electrodes included in these analyses. Frontal sites (AF3, F1, FP1, FPz, AF4, F2, FP2) were used to examine the medial prefrontal and right prefrontal EM effects. Parietal-occipital sites (P1, P3, P5, PO3, PO7, O1, $\mathrm{Pz}, \mathrm{POz}, \mathrm{Oz}, \mathrm{P} 2, \mathrm{P} 4, \mathrm{P} 6, \mathrm{PO} 2, \mathrm{PO} 8, \mathrm{O} 2)$ were used to examine the left parietal EM effect. Midline sites ( $\mathrm{FPz}, \mathrm{Fz}$, $\mathrm{FCz}, \mathrm{Cz}, \mathrm{CPz}, \mathrm{Pz}, \mathrm{POz}, \mathrm{Oz}$ ) were also used to examine the anterior to posterior distribution of the left parietal as well as the centro-parietal EM effect and the centro-parietal negative EM effect observed in the SP data.

For the normalized data, time regions revealing significant Electrode Site by Bin interactions (suggesting the presence of different EM effects) were reduced to a single averaged voltage by finding the regions that included the peak of the EM effect but that did not yield Electrode by Bin interactions. The resultant windows, shown in Table 2, comprise the EM effects that were compared between the young and the old. Group (young vs. old) by Bin (100 ms bins within the selected window) repeated measures ANOVAs were conducted on the difference waves (oldnew) to identify differences in timing of the EM effects between the two groups.

\subsubsection{Scalp distribution}

To determine if the scalp distribution of the EM effects were similar in the old and young, a second set of topographic analyses was conducted. To compare the topography between groups, the data were first normalized using the root mean square method described above. Topographic analyses were conducted only for components detectable in the ERPs of both groups.

\section{Results}

\subsection{Behavioral data}

Measures of item discrimination $\left(d_{\mathrm{L}}\right)$ and response bias $\left(c_{\mathrm{L}}\right)$ were based on logistic distributions in a signal detection model [57]. Button press performance, shown in Table 3, indicates that young subjects more accurately discriminated old and new words than the older subjects $[F$ $(1,26)=31.7, P<0.001]$. No differences were revealed between the two groups on the measure of response bias, as both groups were relatively conservative in their judgments. Young women also outperformed the older women on source recognition $[F(1,26)=89.4, P<0.001]$. The size of the aging effect for source memory $(d=4.0)$ was nearly twice as large as the aging effect for item memory

Table 2

Timing and scalp focus of selected EM effects identified in the SP and CSD data

\begin{tabular}{lrr}
\hline & Young & Old \\
\hline SP EM effects & & \\
Centro-parietal & $300-500 \mathrm{~ms} \mathrm{(CPz)}$ & $400-600 \mathrm{~ms}(\mathrm{CPz})$ \\
Right prefrontal & $1100-1300 \mathrm{~ms}(\mathrm{AF} 4)$ & $1000-1200 \mathrm{~ms}(\mathrm{AF} 4)$ \\
Central negativity & $800-1300 \mathrm{~ms}(\mathrm{CPz})$ & $800-1300 \mathrm{~ms}(\mathrm{CPz})$ \\
Parietal negativity & $1200-2000 \mathrm{~ms}(\mathrm{POz})$ & $1200-2000 \mathrm{~ms}(\mathrm{CPz})$ \\
& & \\
CSD EM effects & & $500-600 \mathrm{~ms}(\mathrm{AF} 4)$ \\
Medial prefrontal & $300-600 \mathrm{~ms} \mathrm{(FPz)}$ & $400-600 \mathrm{~ms}(\mathrm{P} 5)$ \\
Left parietal (early region) & $300-500 \mathrm{~ms} \mathrm{(P5)}$ & $1100-1200 \mathrm{~ms}(\mathrm{P} 5)$ \\
Left parietal (late region) & $800-1000 \mathrm{~ms}(\mathrm{P5})$ & $800-1200 \mathrm{~ms}(\mathrm{AF} 4)$ \\
Right prefrontal & $700-1100 \mathrm{~ms}(\mathrm{AF} 4)$ & \\
Parietal negativity & $1400-2000 \mathrm{~ms}(\mathrm{Pz})$ & \\
\hline
\end{tabular}


Table 3

Mean and standard deviation (S.D.) accuracy indexes and reaction times (RTs) for each age group as a function of condition

\begin{tabular}{lrrrrr}
\hline & \multicolumn{2}{l}{ Young } & & & \multicolumn{2}{l}{ Old } \\
\cline { 2 - 3 } \cline { 6 - 6 } & \multicolumn{1}{l}{ Mean } & \multicolumn{1}{l}{ S.D. } & & Mean & \multicolumn{1}{c}{ S.D. } \\
\hline Proportion of hits & 0.92 & 0.05 & & 0.83 & 0.08 \\
Proportion of false alarms & 0.02 & 0.01 & & 0.08 & 0.06 \\
Sensitivity $\left(d_{\mathrm{L}}\right)$ & 6.79 & 1.33 & & 4.39 & 0.87 \\
Response bias $\left(c_{\mathrm{L}}\right)$ & 0.75 & 0.40 & & 0.47 & 0.69 \\
Source accuracy $(I)$ & 0.95 & 0.04 & & 0.67 & 0.10 \\
Target hit RTs & 800.62 & 130.86 & & 965.80 & 176.52 \\
Correct rejection RTs & 803.11 & 108.00 & & 938.76 & 149.62 \\
\hline
\end{tabular}

$(d=2.18)$ (Cohen's $d$; [7]). Table 3 also indicates that young women responded more quickly than the older women during item recognition to both new and old words $[F(1,26)=9.9, P<0.01]$.

\subsection{ERP results}

The mean number of trials entered into the ERP averages elicited by old and new items for the young participants was, respectively, 199 (range $=124-242$ ) and 209 (range $=127-245)$. For the older adults, these values were 141 (range $=52-206)$ and 159 (range $=65-221)$. Fig. 2 shows the grand mean waveforms to old and new words for the young. To make viewing easier, the electrode sites depicted in this and the following figures were selected (from the total of 62) as representative of the major effects observed at the non-depicted scalp sites. Generally, for the young adults, old words are more positive-going than new words from approximately 250 to $650 \mathrm{~ms}$ post-stimulus, comprising medial prefrontal, centro-parietal and subsequent left parietal EM effects. The medial prefrontal and left parietal effects are more conspicuous in the CSD data (Fig. 5) and likely contribute to the centro-parietal effect observed in the surface potential data. This centro-parietal effect in the SP data has been described as the early left parietal EM effect by others [61]. Fig. 2 shows that old words are again more positive than new words from approximately $1000 \mathrm{~ms}$ post-stimulus through the end of the recording epoch. This old/new difference shows a right-prefrontal focus, as reported previously [61,70]. Finally, old words are more negative-going than new words over parietal scalp sites from $1200 \mathrm{~ms}$ through the end of the recording epoch, constituting a parietal negative EM effect. The waveforms of the older adults (Fig. 3) also show robust left parietal EM effects, with old words more positive than new words from approximately 350 to 700 ms post-stimulus. However, older adults do not produce a right prefrontal effect, though they do show the parietal negativity seen in the ERPs of the young in addition to a central negativity that was absent in the ERPs of the young.

Old-minus-new difference waveforms for both groups are superimposed in Fig. 4. The difference waveforms of the young subjects at centro-parietal scalp sites is clearly more positive-going from approximately 250 to $600 \mathrm{~ms}$ compared to the waveforms of the old subjects. In the second half of the epoch, old subjects show a negativegoing difference across much of the scalp, whereas the young show a positive-going difference focused over right frontal scalp sites and a negative-going difference at parieto-occipital sites. These effects can also be seen in the SP and CSD maps for the old-minus-new difference waveforms depicted in Figs. 5 and 6 for the young and the old adults, respectively.

Based on the timing and topographic analyses described in the Materials and methods section, several subcomponents of the EM effect were identified in the SP and CSD data (Table 2). Group comparisons of these components are described below and reported in Table 4.

\subsubsection{Medial prefrontal EM effect}

As shown in row b of Fig. 5, CSD maps of the young show an early onset medial prefrontal EM effect that is significant between 300 and $600 \mathrm{~ms}$ (recall that significant windows were determined with a Condition $\times$ Bin ANOVA across each 100-ms Bin using a Bonferroni-corrected $P$ value $[P=0.0025]$, as described in Section 2.5.1 above). Row b of Fig. 6 shows a similar component in the CSD maps of the old, which appears more right-sided than the medial prefrontal effect of the young. Topographical analyses of the early medial prefrontal effect, using a subset of left, right and medial frontal electrodes (FP1, FP2, AF3, AF4, F1, F2, FPZ), confirmed a more rightsided distribution of the EM effect in the older adults $[F$ $(2.7,70)=2.9, P<0.05,=0.45]$. The effect peaks earlier for younger adults $(400-500 \mathrm{~ms})$ than for the older adults (500-600 ms), as indexed by an interaction of Group and Bin $[F(1,26)=12.5, P<0.01]$. However, the magnitude of the medial prefrontal EM effect did not differ significantly between the two groups (Table 4).

\subsubsection{Centro-parietal EM effect}

The SP data revealed a significant centro-parietal EM effect in the ERPs of the young between 300 and $600 \mathrm{~ms}$, which is depicted in Fig. 5 (row a). This same EM effect, significant between 400 and $600 \mathrm{~ms}$, can also be seen in the maps of the old in Fig. 6, row c. However, the centro-parietal EM effect appears to occur later in the ERPs of the old, which was confirmed by a Group by Bin interaction $[F(2,52)=5.4, P<0.05]$. Additionally, the centro-parietal EM effect of the young (300-500 ms bin) is significantly larger in amplitude compared to that of the old (400-600 ms window) (Table 4).

Topographical analysis of the centro-parietal EM effect was conducted to determine whether this component had a more frontal focus in the ERPs of the old compared to the young. Analysis of normalized data from a midline array of electrodes (see Fig. 1) failed to reveal differences in the scalp distribution between young and old. Thus, though the 


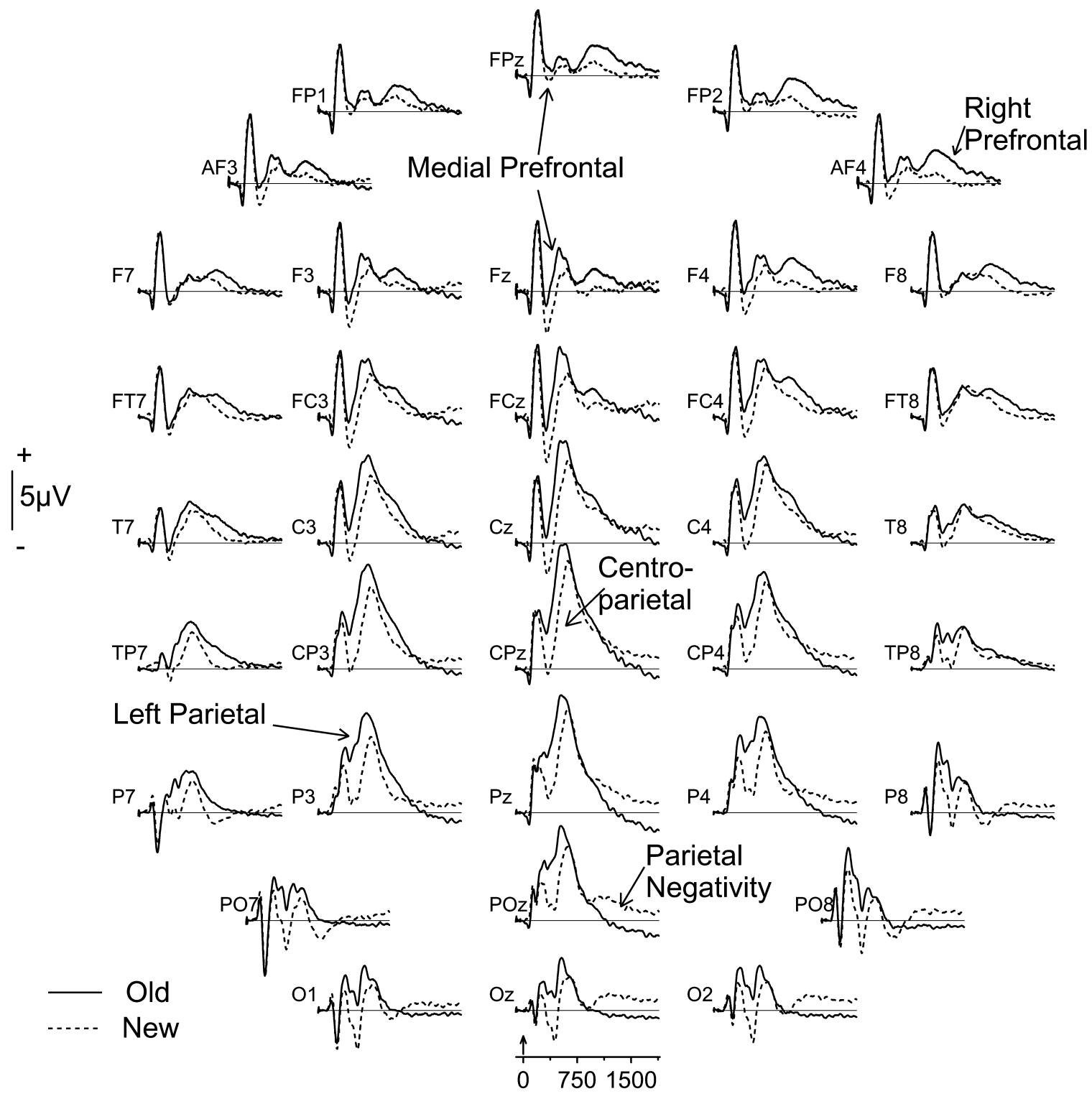

\section{Younger Adults}

Fig. 2. Grand mean ERP waveforms for the young for correctly identified old and correctly rejected new items. Data are depicted for a 2000-ms epoch with a 100-ms pre-stimulus baseline. The depicted electrode sites were chosen for display to be representative of the non-depicted sites and to provide reasonable coverage of the scalp surface.

timing and the size of the effect vary by group, the topographies are statistically indistinguishable.

\subsubsection{Left parietal EM effect}

The left parietal EM effect in the CSD data shows a left-sided focus and lasts for several hundred milliseconds (row d of Figs. 5 and 6). The left-parietal EM effect in the CSD maps corresponds temporally to the centro-parietal EM effect discussed above in the SP data. The initial Condition $\times$ Bin analysis revealed that this left parietal EM effect was significant (i.e., showed reliable old/new differences) from 400 to $600 \mathrm{~ms}$ in the young and from 500 to
$700 \mathrm{~ms}$ in the old. Analysis of the difference waves across three 100-ms bins (300-700 ms) revealed a significant Group by Bin interaction $[F(2,52)=6.6, P<0.01]$ suggesting that the maximal EM effect for the older women (500-600 ms) occurred later than that of the younger women (400-500 ms). However, the magnitude of the left parietal EM effect did not differ significantly between the two groups (Table 4). In subsequent latency regions, the left parietal EM effect is again significant in the younger adults between 800 and $1000 \mathrm{~ms}$ and between 1100 and $1200 \mathrm{~ms}$ in the older adults. Despite these differences in timing, the magnitude of the later aspect of the left parietal 

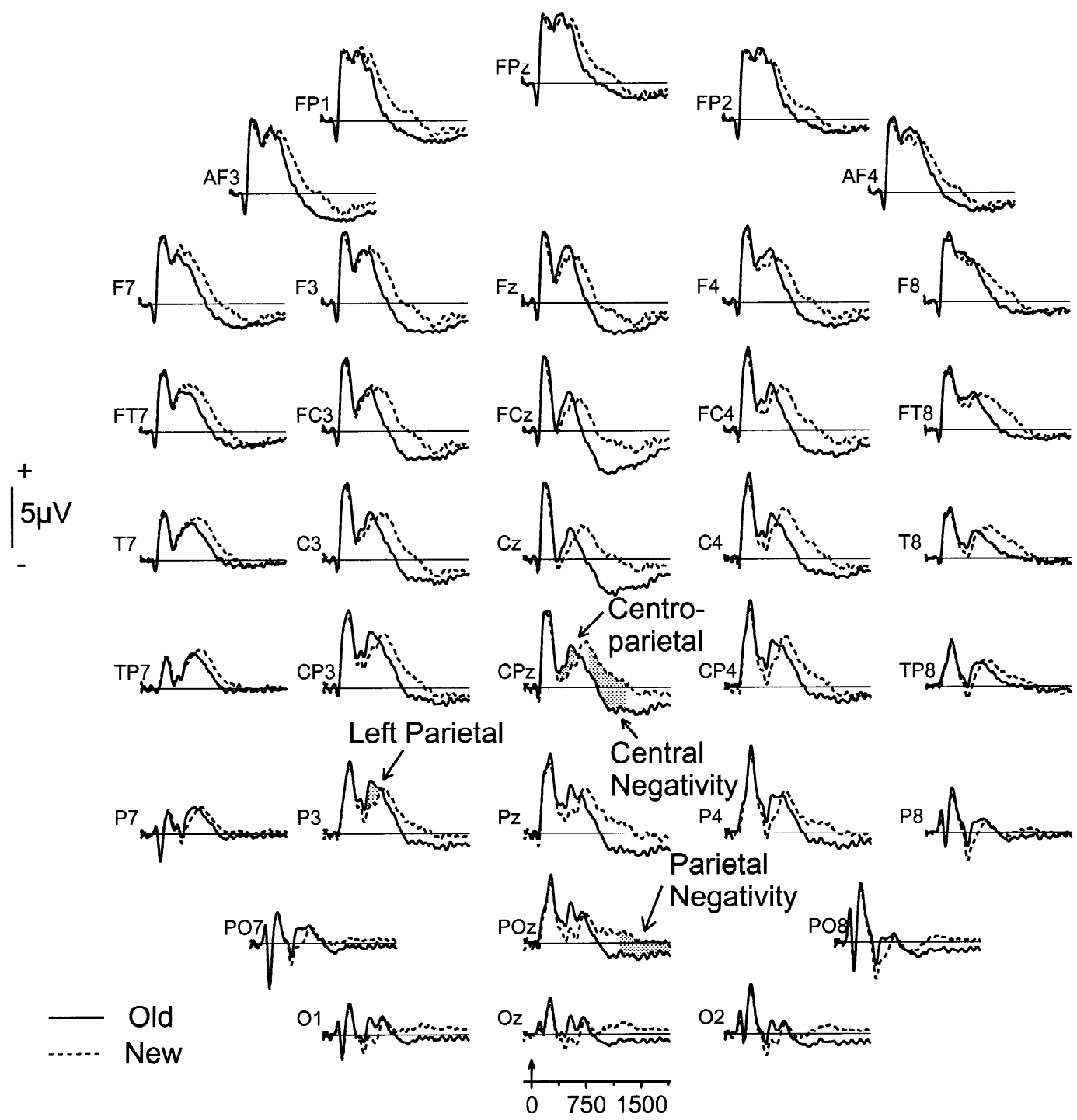

Negativity
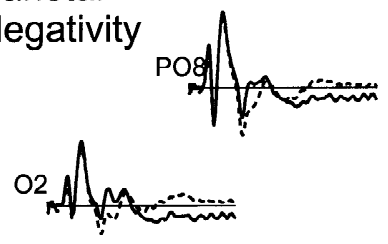

\section{Older Adults}

Fig. 3. Grand mean ERP waveforms for the older subjects for correctly identified old and correctly rejected new items. Calibrations and timing are the same as for Fig. 2.

EM effect does not differ between the two groups (Table 4).

To compare the topography of the left parietal EM effect between groups, the data from a subset of left-sided temporal and parietal electrode sites (see Fig. 1) was submitted to a Group $\times$ Electrode ANOVA. No significant interactions were revealed for either early or late regions of the left parietal EM effect, suggesting that the left parietal EM effect is topographically equivalent across the two groups.

\subsubsection{Right prefrontal EM effect}

The right prefrontal EM effect was apparent in the young in both SP and CSD maps (see Fig. 5, rows e and f). For the SP data, the initial Condition $\times$ Bin analysis re- vealed that this right prefrontal EM effect was significant between 1000 and $1200 \mathrm{~ms}$, with a maximum difference in the 1100-1200 ms window. Though a suggestion of right prefrontal activity can be visualized in the SP maps of the older women (see Fig. 6, rows e and f), this EM effect failed to reach significance at any bin across the recording epoch. As such, group comparisons were not conducted on this component's amplitude.

\subsubsection{Central-parietal negative EM effects}

The ERP data (Fig. 2) and SP maps of the young (Fig. 5 , row e) show a long-lasting negativity that significantly differentiates old and new words from $1200 \mathrm{~ms}$ to the end of the recording epoch, with old words eliciting greater negativity than new words. This difference is maximal 


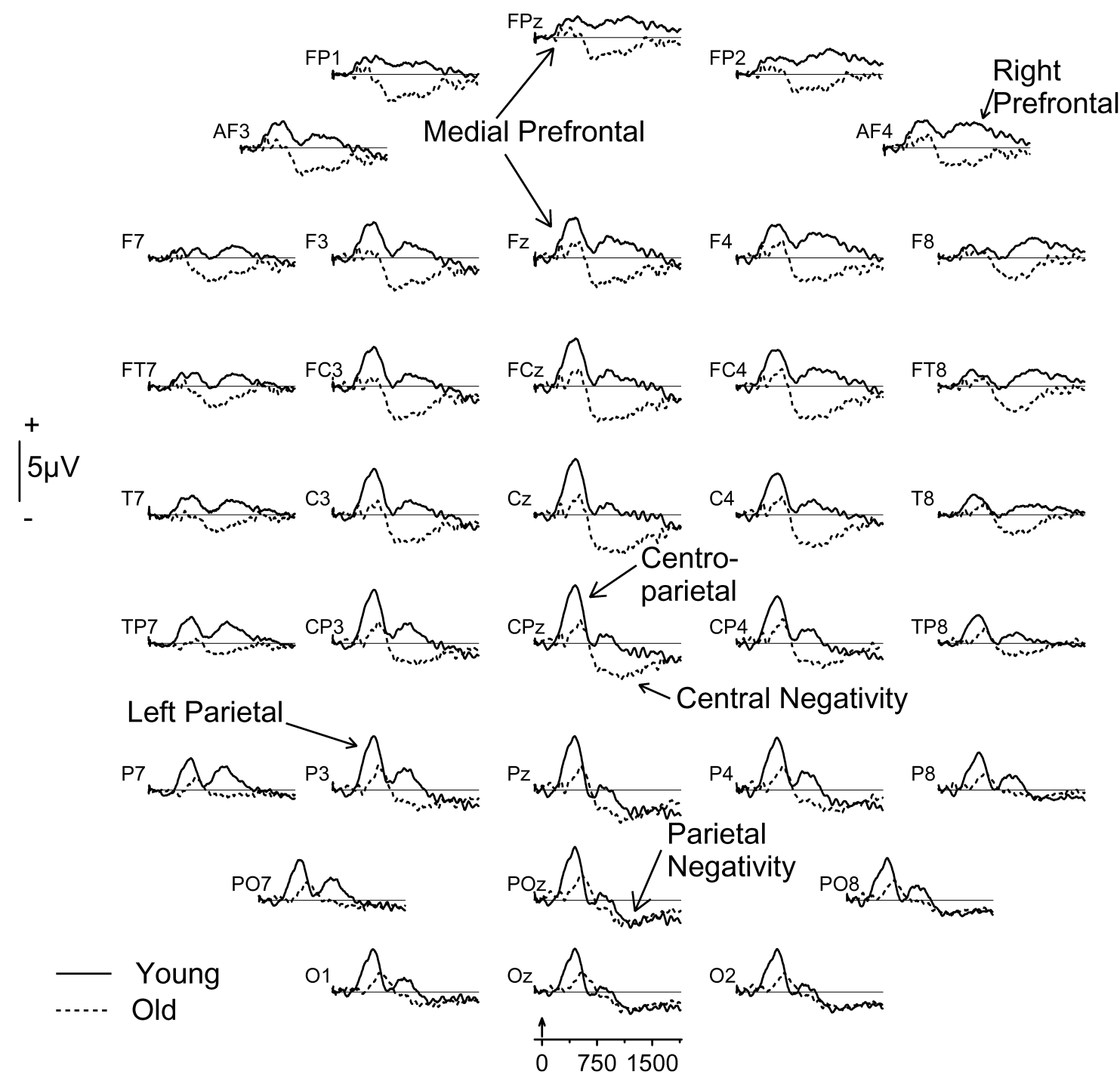

\section{Difference Waveforms}

Fig. 4. Grand mean old-minus-new difference waveforms for young and old adults. Calibrations and timing are the same as for Fig. 2.

between 1200 and $1300 \mathrm{~ms}$ and is focused around the $\mathrm{POz}$ electrode site. The SP maps of the old (Fig. 6, row e) also show a long-lasting negative EM effect. However, the topography appears to differ from that of the young. For the old subjects, this negative EM effect has a more anterior focus $(\mathrm{CPz})$ and is more widely distributed across the scalp. The peak difference occurs between 1000 and $1100 \mathrm{~ms}$ in the old. Topographic analysis comparing the anterior-to-posterior dimensions of this negative EM effect between the two groups revealed a significant interaction of Group and Electrode $[F(7,182)=6.2, P<0.001$, $=0.31]$ verifying that the negativity had a more anterior focus in the old compared to the young. Because of the topographic difference, between-group analyses on these negative EM effects were performed at both $\mathrm{CPz}$ and $\mathrm{POz}$. At the $\mathrm{CPz}$ electrode site, the young did not show a reliable EM effect, resulting in a significantly larger negativity in the ERPs of the older women (Table 4). At the POz scalp site, the negative EM effect did not differ between the two groups.

A negative EM effect can also be observed in the CSD maps of the young (Fig. 5, row f). This negative EM effect is significant from $600 \mathrm{~ms}$ through the end of the recording epoch and is maximal at the $\mathrm{Pz}$ electrode. The old women do not show a clearly focused negative EM effect in their CSD data, suggesting the possibility that their negative EM effect (observed in the SP data) might receive contributions from subcortical structures.

\subsubsection{Summary of ERP episodic memory findings}

Consistent with previous findings from this laboratory [61] and others [34,52], old/new recognition testing with a 
Young Subjects: Difference Waves $\left(0.4 \mu \mathrm{V}\right.$ potentials; $\left.0.02 \mu \mathrm{V} / \mathrm{cm}^{2} \mathrm{CSD}\right)$

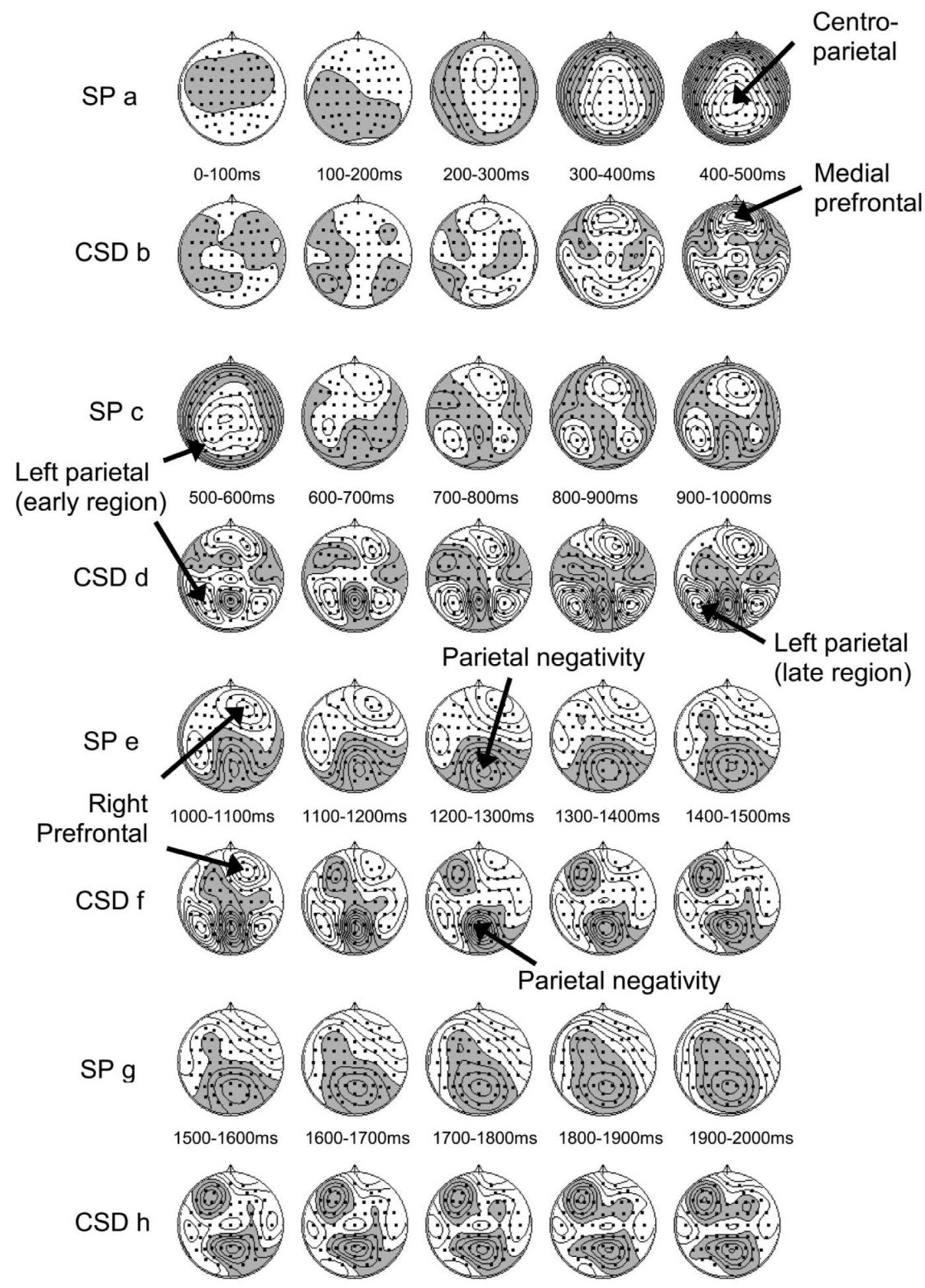

Fig. 5. Surface potential (SP) and current source density (CSD) maps based on the difference waveforms of the young representing successive 100-ms periods of brain activity throughout the $2000 \mathrm{~ms}$ recording epoch. EM effects are labeled. 
Old Subjects: Difference Waves $\left(0.2 \mu \mathrm{V}\right.$ potentials; $\left.0.02 \mu \mathrm{V} / \mathrm{cm}^{2} \mathrm{CSD}\right)$

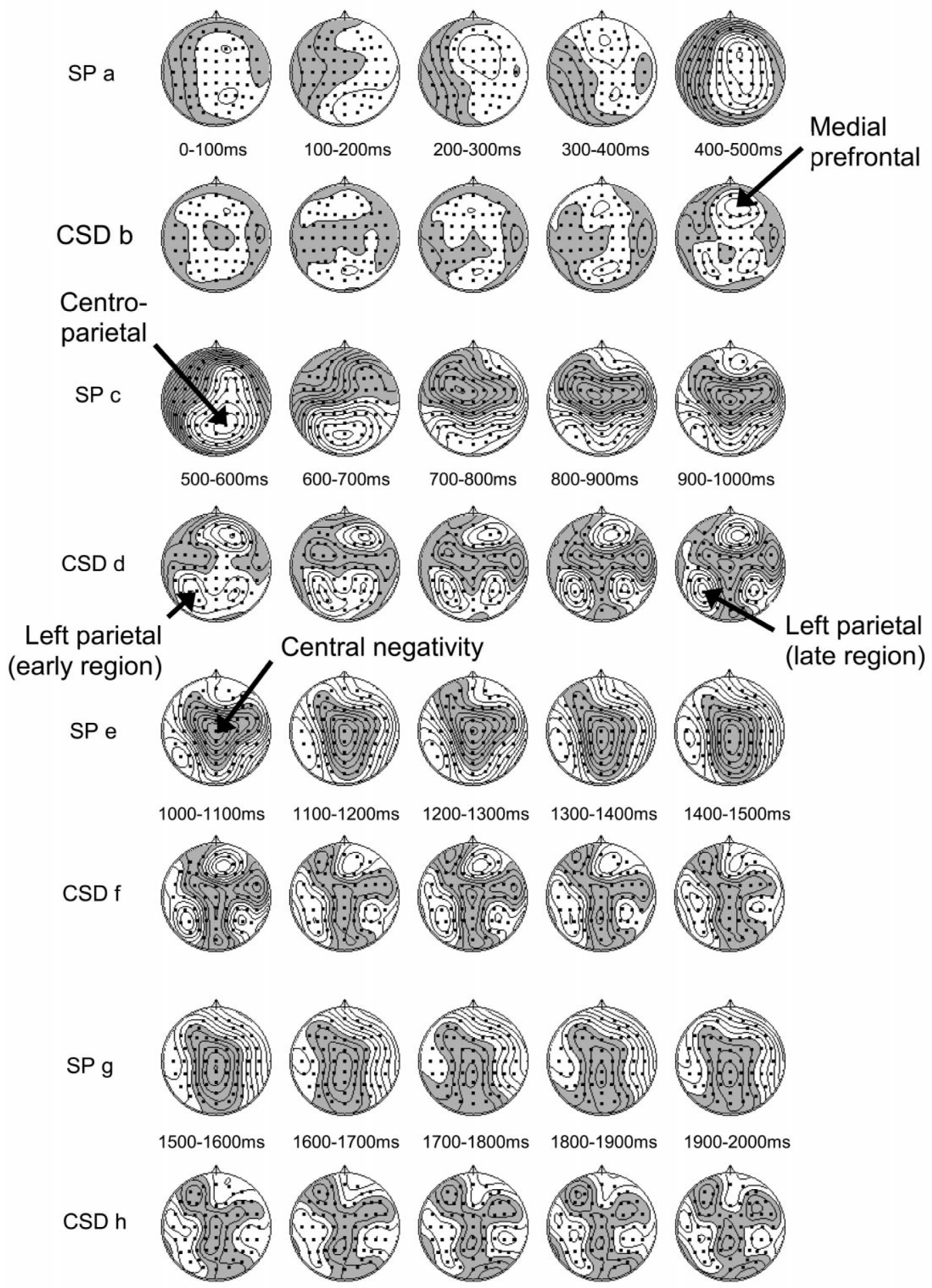

Fig. 6. Surface potential (SP) and current source density (CSD) maps based on the difference waveforms of the old subjects representing successive 100 -ms periods of brain activity throughout the $2000 \mathrm{~ms}$ recording epoch. EM effects are labeled. 
Table 4

Means, standard deviations, and $F$ and $P$ values for the EM effects identified in the SP and CSD data in young and old adults

\begin{tabular}{|c|c|c|c|c|c|c|}
\hline & \multicolumn{2}{|l|}{ Young } & \multicolumn{2}{|l|}{ Old } & \multirow[t]{2}{*}{$F$} & \multirow[t]{2}{*}{$P$} \\
\hline & $M$ & S.D. & $M$ & S.D. & & \\
\hline \multicolumn{7}{|l|}{ SP EM effects $(\mu V)$} \\
\hline Centro-parietal & 4.02 & 1.69 & 1.41 & 0.89 & 25.99 & 0.0001 \\
\hline Right prefrontal & 1.99 & 1.64 & -1.11 & 1.98 & 20.27 & 0.0001 \\
\hline Central negativity & -0.20 & 2.30 & -2.55 & 1.84 & 10.02 & 0.001 \\
\hline Parietal negativity & -1.81 & 2.29 & -1.30 & 1.95 & 0.55 & 0.464 \\
\hline \multicolumn{7}{|l|}{ CSD EM effects $\left(\mu \mathrm{V} / \mathrm{cm}^{2}\right)$} \\
\hline Medial prefrontal & 0.09 & 0.05 & 0.02 & 0.04 & 1.23 & 0.27 \\
\hline Left parietal (early region) & 0.11 & 0.09 & 0.07 & 0.05 & 1.89 & 0.18 \\
\hline Left parietal (late region) & 0.12 & 0.14 & 0.05 & 0.08 & 2.36 & 0.14 \\
\hline Right prefrontal & 0.09 & 0.05 & 0.05 & 0.05 & 4.99 & 0.034 \\
\hline Parietal negativity* & & & & & & \\
\hline
\end{tabular}

* Not tested because this component was not present in the CSD maps of the older adults.

source memory component elicited several temporally and topographically distinct EM effects at the scalp surface. A centro-parietal EM effect was present in the ERPs of both young and old subjects, though it occurred earlier in the ERPs of the young. A later EM effect with a rightprefrontal focus was also revealed in the ERPs of the young, but not in those of the old. These two EM effects were also represented in the CSD data of the young, although the centro-parietal effect had a more left-sided focus in the CSD data than in the SP data. In addition to these two EM effects, the CSD data revealed a medial prefrontal EM effect in both groups that was more rightsided in the ERPs of the older adults. Further, a later parietal negative EM effect was revealed in the SP data of both the young and old participants in addition to a central-parietal negativity that was present only in the ERPs of the older adults. Finally, CSD data showed a late parietal negativity that was present only in the ERPs of the young.

\section{Discussion}

A central aim of the current study was to revise our previous source memory paradigm [61] in order to improve the source accuracy of the older women to investigate whether, with enhanced source memory performance, they would exhibit the right prefrontal EM effect that is observed in the ERPs of the young. The higher source memory performance reported here suggests that the revisions made in the experimental protocol were successful in boosting the performance of the older adults. In fact, source accuracy of the current study's older women $(67 \%)$ was comparable to the source memory accuracy scores of Trott et al.'s younger women (67\%). However, despite enhanced performance, the ERPs of the old failed to show a significant right-prefrontal EM effect, which was again present in the ERPs of the current study's young women. This result will be discussed in light of the frontal deficit hypothesis of cognitive aging.

Despite the higher source memory performance of the old in this study, effects of aging were still obtained, as the younger women significantly outperformed the older women on measures of item and source memory. However, the aging effect size for source memory $(d=4.0)$ was nearly twice that of the aging effect size for item memory $(d=2.2)$. Note that these effect sizes may be somewhat inflated due, in part, to the reduced variability in the scores of the young women, who demonstrated consistently high performance. Nevertheless, the pattern of differences reported is consistent with previous studies (e.g., Refs. $[8,58,61,64])$ and is consistent with the proposal that changes with age are greater in frontal, as opposed to medial temporal lobe areas [67].

The fact that older adults in the current study performed comparably on the source task to younger adults in previous work (using lower memory load and encoding procedures) yet still failed to show a right prefrontal EM effect is inconsistent with the proposal that the frontallyoriented activation is related to retrieval success [34]. These results replicate previous findings from this laboratory [61], as well as ERP [52] and PET [5] findings from other laboratories. However, conflicting ERP data [34] and functional imaging hemodynamic data [2] showing equivalent right prefrontal EM effects in young and old participants stand in contrast to these ERP data.

One important distinction between the current paradigm and that employed by Mark and Rugg [34] involves the type of source retrieval required: temporal vs. perceptual source. As mentioned in the Introduction, a meta-analytic study [58] reported that the aging effect for temporal source $(d=1.17)$ was larger than that for perceptual source $(d=0.8)$. Correspondingly, the older adult's behavioral performance on the voice discrimination task used by Mark and Rugg was higher than the older women's 
performance on the current list discrimination task. In post-test debriefings, several of the older adults in the current study explained that they had difficulty in correctly identifying the source of the test words in part because the two study lists were perceptually indistinct. This hypothesis is consistent with the source monitoring framework proposed by Johnson and co-workers [26,28], which suggests that memory monitoring processes evaluate episodically retrieved information for specific perceptual qualities that help determine the original source. Memories from specific sources commonly have different perceptual qualities, e.g., comparing the perceptual attributes of written text compared to spoken words. The right prefrontal ERP activity has been proposed to reflect processes reflecting the integration of such perceptual information [27].

Mitigating against this interpretation is the robust right prefrontal EM effect revealed in the ERPs of the young women, despite the lack of perceptual distinctiveness between the two study lists. It is possible that participants imposed certain perceptual attributes on the lists in order to distinguish them better and that the right prefrontal effect reported in the young reflects the evaluation of those self-generated perceptual attributes. A more parsimonious interpretation, however, would suggest that the right prefrontal EM effect is not limited to the evaluation of perceptual attributes of the original context, but may include evaluation of other attributes or other cognitive operations, e.g., re-establishing semantic links between list items as a result of using a specific strategy during the study phase, or retrieving a self-generated story developed to enhance encoding and distinguish list membership. Trott et al. [61] proposed that the lack of right prefrontal effect might relate to less efficient strategy use among the old. Future studies may benefit from experimental designs that manipulate strategy-use directly, e.g. the selective interference paradigm [46], in order to explore more methodically the relationship between meta-cognitive strategies and the right prefrontal EM effect.

In addition to the aging effect reported over right prefrontal areas, the data also revealed an aging effect for the centro-parietal EM effect. Although the older women showed a robust centro-parietal EM effect, it occurred later and was smaller than that of the young women. This finding is inconsistent with previous ERP studies [34,61] that reported centro-parietal EM effects in older adults that were statistically indistinguishable from those of younger adults. However, group differences found in the centroparietal EM effect are consistent with the group differences in item recognition performance, as this aspect of the ERP EM effect is thought to reflect aspects of item retrieval $[16,53,54]$. In previous source memory studies $[70,61]$, this activity has been greater for hit trials associated with correct source attribution compared to hit trials associated with incorrect source attribution and for correctly recognized items that are subsequently recalled [50]. As such, it has been interpreted to reflect successful retrieval of the initial episode, i.e., item retrieval with perhaps the addition of certain contextual information. Further evidence comes from amnesic patients with medial temporal lobe damage, who show both deficits in episodic retrieval and reduced centro-parietal EM effects [29]. Other studies of aging have reported a positive correlation between hippocampal volume and memory ability $[13,17]$. These reports would suggest that the reduction in the centro-parietal effect in the current data might reflect changes in temporal lobe function in older participants.

The CSD data provide evidence that the reductions in the centro-parietal EM effect are subcortical in origin. For example, the CSD maps in Fig. 5, row b reflect an absence of centro-parietal activity at midline sites (from 300-500 ms), which is clearly evident in the SP data (Fig. 5, row a). Since CSD data reflect activity emanating primarily from cortical generators, this pattern is consistent with the idea that the centro-parietal EM effect seen in the SP data reflects activity of deep, subcortical generators, presumably hippocampal [29]. The CSD data also show bilateral parietal activity (Fig. 5, row d) that coincides temporally with, and likely contributes to, aspects of the SP centralparietal EM effect. The left-greater-than-right distribution of the bilateral parietal activity in the CSD data (Fig. 5, row d) is consistent with the left-sided focus of the centro-parietal EM effect seen in the SP data. In fact, previous studies have reported what is identified here as the centro-parietal EM effect as the left-parietal EM effect. Based on their similar patterns of response to old and new items, their timing and topography, we assume these to be equivalent. The left-sided asymmetry is consistent with verbal memory deficits shown by patients with unilateral, left medial temporal lobe damage (e.g., Ref. [40]). Importantly, the left parietal EM effect observed in the CSD data did not differ in magnitude or topography between the young and old adults. Thus, the age differences reported for the centro-parietal EM effect in the SP data are likely due to subcortical generators. However, arguing for caution in attributing too much significance to this amplitude difference is the finding that the centro-parietal EM effect did not differ in scalp distribution between young and old. Hence, these data suggest that similar processes may have been engaged by both groups in retrieving item information.

The centro-parietal EM effect is thought to reflect neural activity generated in a number of neocortical structures outside the medial temporal lobe [20]. In addition to the left parietal cortical activity discussed above, the CSD data also reflect activity in medial prefrontal regions that likely contribute to aspects of the SP central-parietal EM effect. The medial prefrontal EM effect reflects the earliest electrophysiological signal that significantly differentiates old and new words. In the young, significant differences between old and new ERPs were revealed between 300 and $600 \mathrm{~ms}$ post-stimulus; the effect for the older particip- 
ants occurred in a 500-600 ms window and was more right-sided than the effect in the young. In dual-process theories of recognition memory [32,24], recognition can be based on familiarity, a general assessment of similarity between study and test items, or on recollection, retrieval of specific information, e.g., perceptual details, of the studied material. Behavioral studies using speed-accuracy tradeoff procedures have determined that familiarity-based recognition judgments occur faster than recollection-based judgments ( $\sim 420$ vs. $\sim 540 \mathrm{~ms}$ post-stimulus, respectively) $[29,37]$. Recent ERP studies have identified a frontal component that may be related to familiarity $[10,11]$. Labeled the FN400 by Curran, this EM effect has been shown to be similar for words and pseudowords [10] and to be similar for deeply and shallowly encoded words [34]. The timing of the medial prefrontal EM effect reported here is consistent with a familiarity-based recognition process. Group differences in the onset of the effect are consistent with the RT data, indicating slower recognition judgments in the old compared to the young. Further, the topography of the medial prefrontal EM effect seen in the young adults is consistent with that of the FN400 reported by Curran $[10,11]$ and similar EM effects observed by others (e.g., Refs. [30,50]). The topography of the medial prefrontal effect was more right-sided in the older adults. However, by examining their CSD maps (Fig. 6, rows b and d), the onset of the medial prefrontal effect (400-500 $\mathrm{ms}$ ) appears more centrally oriented, as in the young. However, the effect is not significant until the 500-600 ms window, when it shifts to right prefrontal scalp areas. A rightward shift is also evident in the CSD maps of the young adults (Fig. 5, rows b and d) starting in the 500-600 $\mathrm{ms}$ window. As such, the topographical differences between the young and old may be accounted for by group differences in the timing of this EM effect. If the medial prefrontal EM effect does, in fact, reflect familiarity, then it should differ very little, if at all, between young and old adults. Group analyses confirmed that no amplitude differences existed in the medial prefrontal effect between the younger and older adults.

Finally, a centro-parietal negative EM effect was observed that appeared more posteriorly $(\mathrm{POz} \mathrm{vs} . \mathrm{Cz})$ in the ERPs of the young compared to those of the old. A previous source memory study reported a similar posterior negative EM effect with a latency of approximately 900 ms [12]. In that study, the authors compared ERP activity in a simple, item recognition memory task to one that required retrieval of source information. The posterior negativity only occurred in the ERPs elicited during the source memory task, suggesting specificity to memory processes related to the recollection of context. Because these investigators used pictorial stimuli whose colors had to be retrieved during the source task, they argued that the late posterior EM effect might have reflected the rerepresentation of the mental image of the remembered item, thus involving posterior/occipital cortex. In the present data, such re-representation may also have been involved, especially for cases in which visualization was used as a means of retrieving the items. The disparate topography of this EM effect in the ERPs of the young and old may be due to its temporal coincidence with the right prefrontal component. Specifically, the right prefrontal positivity in the ERPs of the young may have attenuated the amplitude of the young's central negativity. The attenuating effects of the right prefrontal effect are less marked at more posterior sites, where the parietal negativity of the young is equivalent to that of the older adults. Since the older adults did not show the right prefrontal positivity, the central negativity in their waveforms was not reduced and thus appeared larger than the central negativity of the young.

Alternatively, the central negativity in the older adults may reflect a different post-retrieval process than the process represented by the parietal negativity in the young. The process is likely related to the search for or retrieval of source information, since it occurred after the mean RT response indicating the participant's old/new decision. This interpretation is feasible in light of the CSD data, which revealed evidence of a parietal negativity only in the ERPs of the young adults, suggesting that the neural generators in the young and old adults differ for the surface central-parietal negativity. Coupled with the lack of the right prefrontal EM effect in the older adults, these data are consistent with rapidly accruing data, based mainly on hemodynamic studies, that older adults engage different neural circuits when they retrieve episodic information. Such differences in areas of brain activation have been suggested to serve as a compensatory mechanism in reducing age-related episodic memory deficits (e.g., Ref. [18]). However, based on the current data, a firm conclusion cannot be reached. Further study is required to delineate which cognitive processes are reflected by the parietal negative and the right prefrontal EM effects, and the reasons why they are absent and/or differently distributed in the ERP waveforms of older adults.

In conclusion, dissociation between source memory performance and the presence of the right prefrontal EM effect has been reported, in highly similar fashion to the results of Trott et al.'s [61] study. Despite the fact that the older subjects of this investigation performed better on the source memory task (compared to the older adults of Trott et al.), the ERPs of the older adults again did not show the right prefrontal EM effect that was present in the ERPs of the young subjects. These data provide support for Moscovitch's [41] 'working with memory' proposal, in which the later-onsetting frontally focused EM effect reflects the processing of presumably hippocampally-generated information. Overall, these behavioral and electrophysiological findings are consistent with the hypothesis that changes in memory function with age are likely associated more with changes in frontal lobe function than with changes in medial temporal lobe function. 


\section{Acknowledgements}

The authors gratefully acknowledge Charles L. Brown III for computer programming and technical assistance, Charlotte Trott for assistance in task development and the volunteers for their time and cooperation. This study was supported in part by K01 AG00879-01 and R03 AG1639601 from NIA (D.J.W. Ph.D., Principal Investigator) and AG05213 from NIA and K05 MH01225 from NIMH (D.F., Ph.D., Prinicipal Investigator).

\section{References}

[1] K. Allan, M.D. Rugg, An event-related potential study of explicit memory on tests of cued recall and recognition, Neuropsychologia 35 (1997) 387-397.

[2] L. Backman, O. Almkvist, J. Andersson, A. Nordberg, B. Winblad, R. Reineck, B. Langstrom, Brain activation in young and older adults during implicit and explicit retrieval, J. Cogn. Neurosci. 9 (1997) 378-391.

[3] M.A. Butters, A.W. Kaszniak, E.L. Glisky, P.J. Eslinger, D.L. Schacter, Recency discrimination deficits in frontal lobe patients, Neuropsychology 8 (1994) 343-353.

[4] R. Cabeza, N. Anderson, S. Houle, J. Mangels, L. Nyberg, Agerelated differences in neural activity during item and temporal-order memory retrieval: a positron emission tomography study, J. Cogn. Neurosci. 12 (2000) 197-206.

[5] R. Cabeza, D. Grady, L. Nyberg, R. McIntosh, E. Tulving, S. Kapur, J.M. Jennings, S. Houle, F.I.M. Craik, Age-related differences in neural activity during memory encoding and retrieval: a positronmissions tomography study, J. Neurosci. 17 (1997) 391-400.

[6] R. Cabeza, J. Mangels, L. Nyberg, R. Habib, S. Houle, A.R. McIntosh, E. Tulving, Brain regions differentially involved in remembering what and when: a PET study, Neuron 19 (1997) $863-870$

[7] J. Cohen, Statistical Power Analysis For the Behavioral Sciences, Lawrence Erlbaum, Hillsdale, NJ, 1988.

[8] F.I.M. Craik, J.M. Jennings, Human Memory, Lawrence Earlbaum, Hillsdale, NJ, 1992.

[9] F.I.M. Craik, J.M. McDowd, Age differences in recall and recognition, J. Exp. Psychol.: Learn. Mem. Cognit. 13 (1987) 474-479.

[10] T. Curran, The electrophysiology of incidental and intentional retrieval: ERP old/new effects in lexical decision and recognition memory, Neuropsycholgia 37 (1999) 771-785.

[11] T. Curran, Brain potentials of recollection and familiarity, Mem. Cognit. 28 (2000) 923-938.

[12] Y.M. Cycowitz, D. Friedman, J.G. Snodgrass, Remembering the color of objects: an ERP investigation of source memory, Cereb. Cortex 11 (2001) 322-334.

[13] M.J. de Leon, A.E. George, J. Golomb, C. Tarshish, A. Convit, A. Kluger, S. DeSanti, T. McRae, S.H. Ferris, B. Reisberg, C. Ince, H. Rusinek, M. Bobinski, B. Quinn, D.C. Miller, H.M. Wisniewski, Frequency of hippocampal formation atrophy in normal aging and Alzheimer's disease, Neurobiol. Aging 18 (1997) 1-11.

[14] J. Dywan, L.L. Jacoby, Effects of aging on source monitoring: differences in susceptibility to false fame, Psychol. Aging 5 (1990) 379-387.

[15] M. Fabiani, D. Friedman, Dissociations between recency and recognition memory in aging, Neuropsycholgia 35 (1997) 129-141.

[16] D. Friedman, R. Johnson, Event-related potential (ERP) studies of memory encoding and retrieval: a selective review, Microsc. Res. Techn. 51 (2000) 6-28.
[17] J. Golomb, M.J. de Leon, A. Kluger, A.E. George, C. Tarshish, S.H. Ferris, Neuroimaging and activation of the frontal lobes, in: B.L. Miller, J.L. Cummings (Eds.), The Human Frontal Lobes: Functions and Disorders, Guilford Press, New York, 1993, pp. 196-230.

[18] C.L. Grady, F.I.M. Craik, Changes in memory processing with age, Curr. Opin. Neurobiol. 10 (2000) 224-231.

[19] G. Gratton, M.G. Coles, E. Donchin, A new method for off-line removal of ocular artifact, Electroencephalogr. Clin. Neurophysiol. 55 (1983) 468-484.

[20] R. Guillem, B. N'Kaoua, A. Rougier, B. Claverie, Effects of temporal versus temporal plus extra-temporal lobe epilepsies on hippocampal ERPs: physiopathological implications for recognition memory studies in humans, Cogn. Brain Res. 2 (1995) 147-153.

[21] B. Gurland, R.R. Golden, J.A. Teresi, J. Challop, The SHORTCARE: an efficient instrument for the assessment of depression, dementia and disability, J. Gerontol. 39 (1984) 166-169.

[22] S. Hashtroudi, M.K. Johnson, L.D. Chrosniak, Aging and qualitative characteristics of memories for perceived and imagined complex events, Psychol. Aging 5 (1990) 119-126.

[23] G. Heit, M.E. Smith, E. Halgren, Neuronal activity in the human medical temporal lobe during recognition memory, Brain 113 (1990) 1093-1112.

[24] L.L. Jacoby, Measuring recollection: strategic versus automatic influences of associative context, in: C. Umilta, M. Moscovitch (Eds.), Attention and Performance, Conscious and Nonconscious Information Processing, Vol. 15, MIT Press, Cambridge, MA, 1994.

[25] J.S. Janowsky, A.P. Shimamura, L.R. Squire, Source memory impairment in patients with frontal lobe lesions, Neuropsychologia 27 (1989) 1043-1056.

[26] M.K. Johnson, S. Hashtroudi, D. Lindsay, Source monitoring, Psychol. Bull. 114 (1993) 3-28.

[27] M.K. Johnson, J. Kounios, S.F. Nolde, Electrophysiological brain activity and memory source monitoring, Neuroreport 8 (1996) $1317-1320$.

[28] M.K. Johnson, C.L. Raye, Reality monitoring, Psychol. Rev. 88 (1981) 67-85.

[29] R. Johnson, On the neural generators of the P300: evidence from temporal lobectomy patients, in: G. Karmos, M. Molnar, V. Csepe, I. Czigler, J.E. Desmedgt (Eds.), Perspectives of Event-Related Potentials Research EEG, Elsevier, New York, 1995, Suppl. 44.

[30] R. Johnson Jr., K. Kreiter, B. Russon, J. Zhu, A spatio-temporal analysis of recognition-related event-related brain potentials, Int. J. Psychophysiol. 29 (1998) 83-104.

[31] A. Koriat, H. ben-Zur, D. Sheffer, Telling the same story twice: output monitoring and age, J. Mem. Language 27 (1988) 23-39.

[32] G. Mandler, Recognizing: the judgement of previous occurrence, Psychol. Rev. 87 (1980) 252-271.

[33] J. Mangels, Strategic processing and memory for temporal order in patients with frontal-lobe lesions, Neuropsychology 11 (1997) 1-15.

[34] R.E. Mark, M.D. Rugg, Age effects on brain activity associated with episodic memory retrieval: an electrophysiological study, Brain 121 (1998) 861-873.

[35] R. Mayeux, Y. Stern, J. Rosen, J. Leventhal, Depression, intellectual impairment and Parkinson's disease, Neurology 31 (1981) 645-650.

[36] G. McCarthy, C.C. Wood, Scalp distributions of event-related potentials: An ambiguity associated with analysis of variance models, Electroencephalogr. Clin. Neurophysiol. 62 (1985) 203208.

[37] N. McElree, P.O. Dolan, L.L. Jacoby, Isolating the contributions of familiarity and source information to item recognition: a time-course analysis, J. Exp. Psychol.: Learn. Mem. Cognit. 25 (1999) 563-582.

[38] J.S. McIntyre, F.I.M. Craik, Age differences in memory for item and source information, Can. J. Psychol. 41 (1987) 175-192.

[39] B. Milner, P. Corsi, G. Leonard, Frontal lobe contribution to recency judgements, Neuropsychologia 29 (1991) 601-618.

[40] R.G. Morris, S. Abrahams, C.E. Polkey, Recognition memory for words and faces following unilateral temporal lobectomy, Br. J. Clin. Psychol. 34 (1995) 571-576. 
[41] M. Moscovitch, Memory and working with memory: evaluation of a component process model and comparison with other models, in: D.L. Schacter, E. Tulving (Eds.), Memory Systems 1994, Oxford University Press, New York, 1994, pp. 269-310.

[42] P.L. Nunez, Electrical Fields of the Brain, Oxford University Press, New York, 1981.

[43] M.R. Nuwer, G. Comi, R. Emerson, A. Fagslang-Frederiksen, J.M. Guerit, IFCN standards for digital recording or clinical EEG, Electroencephalogr. Clin. Neurophysiol. 106 (1998) 259-261.

[44] A.J. Parkin, N.M. Hunkin, B.M. Walter, Relationships between aging, frontal lobe function, and memory for temporal and spatial information, Neuropsychology 9 (1995) 304-312.

[45] M. Petrides, Functional specialization within the dorsolateral frontal cortex for serial order memory, Proc. Royal Soc. London, Ser. B 246 (1991) 299-306.

[46] E. Pezaris, M.B. Casey, Girls who use 'masculine' problem-solving strategies on spatial task: proposed genetic and environmental factors, Brain Cognit. 17 (1991) 1-22.

[47] T.W. Picton, D.O. Lins, M. Scherg, The recording and analysis of event-related potentials, in: F. Boller, J. Grafman (Eds.), Handbook of Neuropsychology X, Elsevier, Amsterdam, 1995, pp. 3-73.

[48] M.D. Rugg, M.G.H. Coles, Electrophysiology of Mind: EventRelated Brain Potentials and Cognition, Oxford University Press, New York, 1995.

[49] M.D. Rugg, P.C. Fletcher, C.D. Frith, R.S.J. Frackowiak, Differential activation of the prefrontal cortex in successful and unsuccessful memory retrieval, Brain 119 (1996) 2073-2083.

[50] M.D. Rugg, A.M. Schloerscheidt, R.E. Mark, An electrophysiological comparison of two indices of recollection, J. Mem. Language 39 (1998) 69.

[51] D.L. Schacter, C.R. Savage, N.M. Alpert, S.L. Rauch, M.S. Albert, The role of hippocampus and frontal cortex in age-related memory changes: a PET study, Neuroreport 7 (1996) 1165-1169.

[52] A.J. Senkfor, C.V. Petten, ERP measures of source and item memory in young and elderly subjects, Annual Meeting of the Society for Psychophysiological Research, Vancouver, 1996.

[53] M.E. Smith, Neurophysiological manifestations of recollective experience during recognition memory judgements, J. Cogn. Neurosci. 5 (1993) 1-13.

[54] M.E. Smith, K. Guster, Decomposition of recognition memory event-related potentials yields target, repetition and retrieval effects, Electroencephalogr. Clin. Neurophysiol. 63 (1993) 145-159.

[55] M.E. Smith, E. Halgren, Dissociation of recognition memory components following temporal lobe lesions, J. Exp. Psychol.: Learn. Mem. Cognit. 15 (1989) 50-60.

[56] M.E. Smith, J.M. Stapleton, E. Halgren, Human medial temporal lobe potentials evoked in memory and language tasks, Electroencephalogr. Clin. Neurophysiol. 63 (1986) 145-159.
[57] J.G. Snodgrass, J. Corwin, Pragmatics of measuring recognition memory: application to dementia and amnesia, J. Exp. Psychol.: Gen. 117 (1988) 34-50.

[58] W. Spencer, N. Raz, Differential effects of aging on memory for content and context: a meta-analysis, Psychol. Aging 10 (1995) $527-539$.

[59] L.R. Squire, S. Zola-Morgan, The medial temporal memory system, Science 253 (1991) 1380-1386.

[60] C. Trott, D. Friedman, W. Ritter, M. Fabiani, Item and source memory: differential age effects revealed by event-related potentials, Neuroreport 8 (1997) 3373-3378.

[61] C. Trott, D. Friedman, W. Ritter, M. Fabiani, Episodic priming and memory for temporal source: event-related potentials reveal agerelated differences in prefrontal function, Psychol. Aging 14 (1999) 390-413.

[62] A.J. Senkfor, C. Van Petten, ERP measures of source and item memory in young and elderly subjects, Poster session presented at the Annual Meeting of the Society for Psychophysiological Research, Vancouver, October 1996.

[63] D. Wechsler, Wechsler Memory Scale, Psychological Corporation, San Antonio, TX, 1997.

[64] D.J. Wegesin, D. Friedman, N. Varughese, Y. Stern, Effects of estrogen therapy and aging on memory-related ERPs, J. Cogn. Neurosci. Suppl. (2000) 134.

[65] D.J. Wegesin, D. Jacobs, N.R. Zubin, P.R. Ventura, Y. Stern, Source memory and encoding strategy in normal aging, J. Clin. Exp. Neuropsychol. 22 (2000) 455-464.

[66] D.J. Wegesin, C.A. Nelson, Effects of inter-item lag on recognition memory in seizure patients preceding temporal lobe resection: evidence from event-related potentials, Int. J. Psychophysiol. 37 (2000) 243-255.

[67] R. West, An application of prefrontal cortex function theory to cognitive aging, Psychol. Bull. 120 (1996) 272-292.

[68] E. Wilding, In what way does the parietal ERP old/new effect index recollection?, Int. J. Psychophysiol. 35 (2000) 81-87.

[69] E. Wilding, M.C. Doyle, M.D. Rugg, Recognition memory with and without retrieval of context: An ERP study, Neuropsychologia 33 (1995) 1-25.

[70] E. Wilding, M.D. Rugg, An event-related potential study of recognition memory with and without retrieval of source, Brain 119 (1996) 889-905.

[71] E. Wilding, M.D. Rugg, Event-related potentials and the recognition memory exclusion task, Neuropsychologia 35 (1997) 119-128.

[72] E.M. Zelinski, L. Light, Young and older adult's use of context in spatial memory, Psychol. Aging 3 (1988) 99-101. 